\title{
An Energy Management Model to Study Energy and Peak Power Savings from PV and Storage in Demand Responsive Buildings
}

\author{
Fakeha Sehar (sehaf0@vt.edu) ${ }^{\mathrm{a}}$, Manisa Pipattanasomporn ${ }^{\mathrm{a}}$ and Saifur Rahman ${ }^{\mathrm{a}}$
}

${ }^{\text {a }}$ Virginia Tech-Advanced Research Institute, Arlington, VA, 22203 USA

Abstract - Demand Response (DR) applications along with strategically deployed solar photovoltaic (PV) and ice

storage systems at the building level can help reduce building peak demand and energy consumption. Research shows that no work has been carried out to study the impact of integrated control of PV and ice storage on improving building operation and energy savings in demand responsive buildings. This can enable building operators to take advantage of different electricity prices and enable utilities to spread the demand over whole day. This research presents a model to study coordinated control of building end-use loads including cooling, lighting and plug loads, together with PV and ice storage integrated with packaged air conditioning (AC) units. This is used to study their impacts on peak demand and energy consumption in a simulated medium-sized office building located in Virginia/Maryland, U.S. area. Research findings provide an improved understanding of the contribution of DR, solar PV and ice storage systems towards reducing building peak electricity demand and energy consumption while being sensitive to occupant thermal and lighting needs.

Keywords-Demand responsive commercial buildings, Integrated automation, PV, Ice storage integrated with packaged AC, Smart grid

\section{Introduction}

Optimized peak demand reductions at the building level by means of coordinated control of building loads (i.e., demand response or DR), PV and ice storage systems can play a major role in flattening the building load shape, decreasing its peak electricity consumption, and at the same time help mitigate grid stress conditions when needed. Allowing buildings to be demand-responsive by controlling HVAC (Heating, Ventilation and Air Conditioning), lighting and plug loads based on demand reduction signals from the grid has proven to provide tremendous savings. Studies [1-8] have estimated savings for lighting load control strategies - including harvesting daylight, dimming and on/off strategies; and HVAC load control strategies - including global temperature adjustment of zones and systemic adjustments to the air distribution and cooling systems. Authors in [9] investigate the optimal control of each thermal zone's cooling load during a DR event while being sensitive to occupant thermal comfort. Authors in $[10,11]$ present a control algorithm to manage few local office plug loads to meet the load shedding target while minimizing occupant inconvenience. 
Buildings can be equipped with renewable energy technologies, such as PV or micro-wind generators. Field trials of urban

building mounted micro-wind generators show that they generate less energy than predicted owing to insufficient wind resource $[12,13]$. In addition, micro-wind generators suitability for roof mounting is questionable in urban environment due to complexity of wind distribution. PV is a well-known technology and authors in [14] highlight its emerging trends and advanced applications. Hence particular attention is given to PV in this study. PV, located either on building rooftop or integrated to building façade, produces electricity during daytime. PV has potential to reduce building peak demand; however, a large fraction of PV electricity generation occurs when the demand is moderate. Studies in [15-17] report that DR can facilitate the integration of intermittent renewable generation and provide required ancillary services. Authors in [18] develop the load behavior of office buildings, which demand electrical energy during high daytime prices. Demand side management is utilized to shift demand to low prices and a PV system can be utilized to reduce demand during high tariffs. Authors in [19] evaluate the impact DR capability on PV penetration for residential customers. Customers with higher DR capability are able to accept more PV capacity due to slow decrease in the marginal revenue for new installed PV.

In addition to DR and PV, storage can shift building peak demand to off-peak periods. In this study particular attention is given to ice storage which is an emerging technology that can potentially shift building air-conditioning (AC) demand - which constitutes about $17.8 \%$ of total electricity consumption in buildings, located in the South-Atlantic division (Virginia/Maryland area) of U.S., [20] to off-peak periods and optimize energy costs. Doing so eliminates chiller (an end-use load) operation or modulates its output in accordance with cooling load requirements and grid needs. From a grid's perspective, an ice storage unit can serve as an effective load management device that can result in higher utilization of the energy infrastructure, provide higher reliability and flexibility to grid operators in managing renewable generation variability [21]. Research studies [22, 23] provide a comprehensive description of ice storage systems and propose design guidelines. The ability to provide low chilled water temperatures, reduce fans and ducts sizes, introduce less humid air in occupied spaces and less storage tank's volume makes ice storage systems an ideal candidate for thermal energy storage [24]. Authors in [25] show energy consumption and peak demand savings by ice storage systems for large and medium-sized office buildings located in diverse climate zones. Authors in [21] conclude that thermal storage is a load management tool and its use can be integrated into building HVAC control systems to generate value for electricity provider in exchange for a financial reward for the building owner. Authors in [26] analyze thermal energy storage potential in load profile management which has not been systematically developed as yet. Authors in [27] couple thermal energy storage with a conventional AC system to perform energy-demand management in Saudia Arabia, where cooling load is high. Reduced energy consumption, lower operation costs and downsizing of chiller plant are achieved as a result. Authors in [28] evaluate the application of cool storage AC in commercial buildings as a demand side management program used to improve system load factor and efficiency of electricity usage. Results show that the technology is a viable resource in 
generation power expansion planning and can reduce the need for new generation resources. Authors in [29] analyze

performance of different energy storage devices in a building energy system, whose operation is formulated as an energy cost minimization problem, in a micro grid environment and conclude that thermal storage provides effective energy cost savings in multiple scenarios of demand and solar radiation profiles. Authors in [30] present cost analysis of a hybrid cooling system that uses thermal energy storage and AC powered by PV to meet a residential building's cooling load during peak hours. Historically ice storage systems have been applied to large commercial buildings and have been integrated with chillers. Mostly small and medium-sized commercial buildings have packaged AC units and if ice storage systems can be integrated with these, its deployment potential could be high [31].

Building owners want to make buildings demand responsive so that they can participate in electricity market. Literature review shows that there are studies which discuss coupling of thermal storage with conventional AC, generating power with a rooftop PV or employing DR strategies at the consumer side to reduce peak demand. However, no work has been carried out to study the impact of deploying various combinations of PV and ice storage to generate additional benefits, including clean energy generation from PV and valley filling from ice storage, from demand responsive buildings. Building owners can take advantage of different electricity prices during peak and off-peak hours and utilities can spread the demand over whole day. DR, on-site renewable and storage can reduce the investment cost, installed capacity of power plants and its $\mathrm{CO}_{2}$ emission. This paper bridges this knowledge gap by providing an integrated automation model for managing building end-use loads, ice storage and PV systems in responding to utility DR signals, while satisfying occupant thermal and lighting needs. It also quantifies peak load reduction and energy savings potentials of a commercial building through the use of viable technologies (i.e., DR, PV and ice storage systems). Since PV generation is weather dependent and may not match with the time of peak demand, utilizing a combination of DR, PV and ice storage system can serve as a unique solution to optimize electricity usage in buildings. Integrated automation of DR, PV and ice storage can be used to generate various load shapes, thereby flattening buildings' load curve and providing energy savings and peak demand reduction opportunities. The model presented is validated by experimentation conducted on a simulated medium-sized office building in EnergyPlus, a building energy simulation tool.

\section{Models of building and its loads by type, PV and ice storage}

This section summarizes the simulated medium-sized office building model, together with the model development of PV and ice storage systems, used as a basis to develop the proposed integrated automation model.

\subsection{Modeling medium-sized office building and its loads by type in EnergyPlus}

EnergyPlus version 8.3 is used for this simulation study. The simulated medium-sized office building model is based on the Department of Energy (DOE)'s medium-sized office reference building model available in [32], reflecting buildings in the Virginia/Maryland, U.S. area with the post-1980 construction. According to the 2012 CBECS (Commercial Buildings Energy 
Consumption Survey) data, about 49\% of office buildings in the U.S. have been constructed between year1980 to 2012 [33] which represents majority of office buildings. The weather data used is of Ronald Reagan Washington National airport, USA available from [34].

Building construction: The simulated medium-sized office building for this study is a $4,980 \mathrm{~m}^{2}$ three-story building. It is rectangular shaped $50 \mathrm{~m}$ by $33 \mathrm{~m}$. Its envelope constructions include steel-framed walls, flat roof with insulation above the deck and slab-on-grade floors. Windows have the height of $1.22 \mathrm{~m}$ and are distributed evenly in continuous ribbons around the perimeter of the building.

Building internal loads: Each floor of the simulated medium-sized office building has a packaged rooftop variable air volume (VAV) system (which vary air volume supplied to the zones). For a summer weekday from 6am to $10 \mathrm{pm}$ the normal cooling set point is $24^{\circ} \mathrm{C}$. During off-hours set back strategy is applied and the cooling temperature set point is $26.7^{\circ} \mathrm{C}$. The simulated building has five thermal zones, four perimeter zones and one core zone, on each floor. The HVAC load model comprises Direct Exchange (DX) cooling unit with VAV fans available in EnergyPlus. The average ambient electric lighting power density for the entire simulated building is $16.89 \mathrm{~W} / \mathrm{m}^{2}$. Office buildings have plug loads, such as office equipment, refrigerators, coffee makers, beverage vending machines. The type and quantity of plug load equipment for the simulated medium-sized office building are used as per [35]. To simulate plug loads in this study, dynamic plug load models with 1-minute intervals for various office equipment presented in [36] are used for this study. Based on these models, the plug load power density for the entire simulated building is $7.86 \mathrm{~W} / \mathrm{m}^{2}$. Occupant density is 5.38 persons per $100 \mathrm{~m}^{2}$ of gross floor area.

Building operation: The simulated building follows typical occupancy patterns for office buildings with peak occupancy between $8 \mathrm{am}$ to $5 \mathrm{pm}$ on weekdays and a decrease during the lunch time between 12 noon to $1 \mathrm{pm}$. The HVAC system is "on" one hour before occupants arrive the building to bring the space to the desired temperature and is "off" one hour after most of the occupants have left the building from $6 \mathrm{am}$ to $11 \mathrm{pm}$. $90 \%$ lights are energized from $8 \mathrm{am}$ to $5 \mathrm{pm}$ and $5 \%$ remain energized from $11 \mathrm{am}$ to $5 \mathrm{am}$.

\subsection{Modeling PV in EnergyPlus}

A grid tied PV is modeled for the simulated medium-sized office building in EnergyPlus to allow feeding the excess PV generation to the grid.

PV module: LG PV module, LG230M1C, parameters have been utilized for modeling purposes. Each modeled PV module has an area of $1.6 \mathrm{~m}^{2}$. The Equivalent One-Diode model, available in EnergyPlus, is used for PV modeling in this study, the description of which is provided in [37]. The following assumptions are used to develop the PV model in EnergyPlus:

PV orientation and tilt: The modeled medium-sized office building is located at latitude $38.87^{\circ}$, so the best tilt angle for summer is the latitude times 0.93 minus $21^{\circ}$ [38] which is $15.14^{\circ}$. The orientation and tilt of the system impact how much of the 
available irradiance the system can collect. The optimal orientation or surface azimuth is true south and the optimal tilt is equal to the latitude. However, using the tilt angle lower than the location's latitude during summer months favors peak production and minimizes the cost of racking, mounting hardware and damage due to wind [39].

PV area: The simulated medium-sized office building's roof has an area of $1660.73 \mathrm{~m}^{2}$, which limits the size of PV arrays along with the customer's budget. Reports [40-42] conclude that in the U.S. about $63 \%$ of all commercial roofs are flat and $60 \%$ to $65 \%$ of rooftop space is suitable for PV. Authors in [43] estimate that $5 \%$ of flat rooftop buildings are covered by HVAC equipment, shadowing about $35 \%$ of roof and allowing flat roofs to have $65 \%$ space available for PV. Authors in [44] suggest $70 \%$ of flat roof is available for PV installation. In view of these studies PV is assumed to cover about $65 \%$ of the simulated medium-sized office building's roof area. Spacing between rows of PV modules can be calculated based on site's latitude, the desired solar window and the modules' height and tilt angle. If incorrectly spaced, tops of tilted row of PV modules can shade the bottom of behind row. The modeled medium-sized office building is located at latitude $38.87^{\circ}$, longitude $-77.03^{\circ}$, the PV module's height is $0.986 \mathrm{~m}$ and the tilt angle is $15.14^{\circ}$. An inter-row spacing of $0.6 \mathrm{~m}$, calculated using [45], is sufficient to avoid shading on winter solstice, the day when the sun is lowest in the sky, for a solar window from around 10am to 2 pm. This allows the maximum of $450 \mathrm{PV}$ modules (30 parallel strings of 15 modules in series) to be installed. The total PV area, along with interrow spacing, is calculated as $1074 \mathrm{~m}^{2}$ out of the entire building's roof area of $1660.73 \mathrm{~m}^{2}$, which is equivalent to about $65 \%$ of the building roof area. Installed PV panels maximum power output is about $104 \mathrm{kWp}$.

Solar radiation: Incident solar radiation on the PV surface is calculated using algorithms which are used for all other exterior surfaces. The direct, diffuse and reflected solar radiation is calculated based on surface geometry. EnergyPlus takes into account shading of PV surface by trees or other buildings. Shade on as little as $5-10 \%$ of an array can predictably reduce its output by over $80 \%$ [46]. The PV surface may reduce the incident radiation on the roof beneath it; this partial transmission through a semitransparent shading surface is also calculated by EnergyPlus. Using the Equivalent One-Diode model and the assumption that panels always operate at maximum power point, DC power output is calculated.

Inverter model: The PV to inverter sizing ratio $\left(R_{S}\right)$ defines the relationship between PV peak power generated at Standard Test Conditions (STC) $\left(1000 \mathrm{~W} / \mathrm{m}^{2}\right.$ and $\left.25^{\circ} \mathrm{C}\right)$ to the nominal $\mathrm{AC}$ power rating of the inverter as shown in Equation 1 [47]. If PV frequently operates at high ambient temperatures, i.e. does not frequently operates at maximum power or is installed at a low tilt angle, the DC-STC power rating of PV is considered higher than the AC output rating of the inverter; typical range of $R_{s}$ is 0.80 to 1.30 [48]. An extremely undersized inverter will be clipping PV output most of the time and an oversized inverter will spend more time operating less efficiently. Inverters are usually undersized as the STC conditions at which PV is rated are less likely to occur in real world conditions [48]. PV output derates with time due to soiling and aging.

$$
R_{S}=\frac{P_{D C(S T C)}}{P_{A C(\text { Nominal })}}
$$


Where $R_{S}$ is the PV to inverter sizing ratio; $P_{D C(S T C)}$ is the PV peak power at $\mathrm{STC}$ conditions $104 \mathrm{kWp} ; P_{A C \text { (Nominal) }}$ is the nominal $\mathrm{AC}$ power rating of inverter.

For $R_{S}$ of 1.09 , inverter nominal $\mathrm{AC}$ power rating is $95 \mathrm{~kW}$ from Equation 1. Inverter data, including make and model, available in [49] is used for modeling inverter in EnergyPlus. An inverter with rated maximum continuous power of $95 \mathrm{~kW}$ (Solectria PVI 90kW-480Vac) [50] is selected. The inverter's nominal input voltage is $390 \mathrm{~V}$ and the power consumed during standby is less than $1 \mathrm{~W}$. Inverter efficiencies at nominal input voltage and percentage of rated power are shown in Table 1.

Table.1 Inverter efficiencies at nominal input voltage and percentage of rated power

\begin{tabular}{|c|c|}
\hline $\begin{array}{c}\text { Output Power at nominal voltage } \\
\text { (\% of rated) }\end{array}$ & $\begin{array}{c}\text { Efficiency } \\
(\%)\end{array}$ \\
\hline 10 & 89.4 \\
\hline 20 & 94.7 \\
\hline 30 & 97.8 \\
\hline 50 & 98.0 \\
\hline 75 & 97.1 \\
\hline 100 & 96.0 \\
\hline
\end{tabular}

The inverter "Look Up Table" model is used in this study. The inverter efficiency is applied linearly to derate the energy production. The inverter capacity forms a limit for power production from a PV generator.

Figure 1 shows the axonometric view of the simulated medium-sized building with installed PV panels covering $65 \%$ of building roof area and casting shadows on the roof.

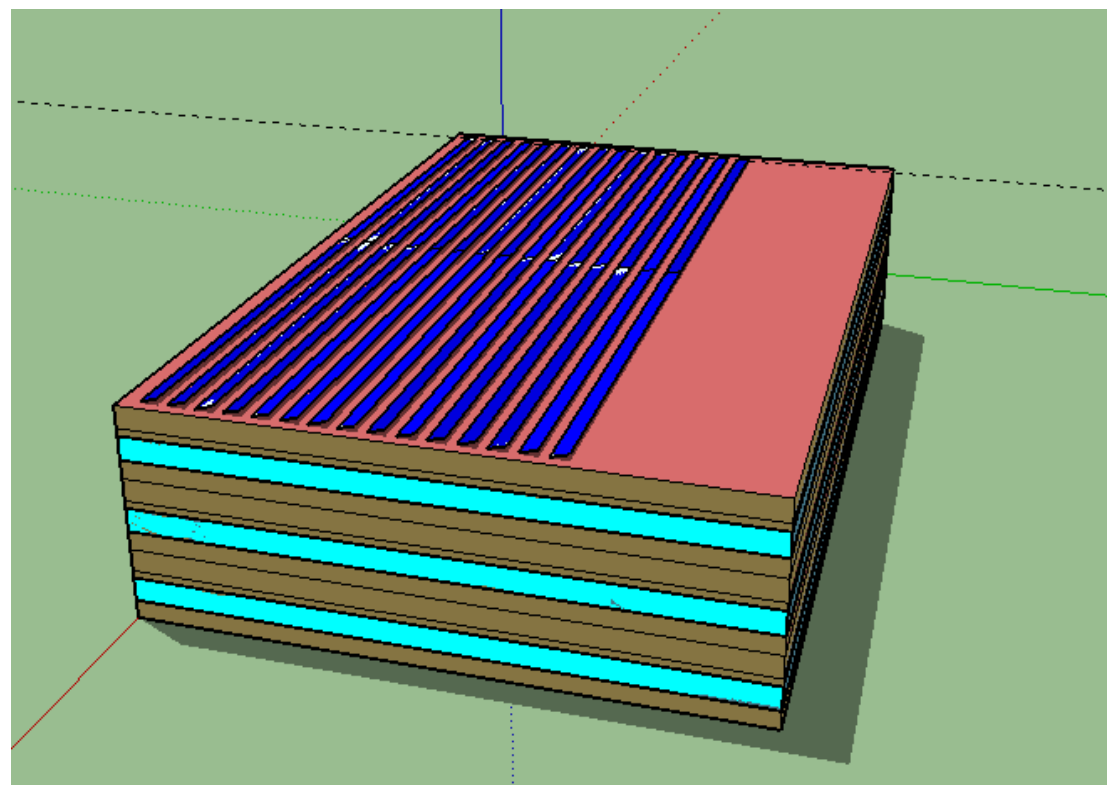

Fig.1 Axonometric view of the simulated medium-sized office building with installed PV panels

\subsection{Modeling ice storage unit in EnergyPlus}

Cooling contributes significantly to building peak load during summers, and ice storage can shift the cooling demand from peak to off-peak periods. 
Ice storage integrated with DX: EnergyPlus provides modeling of an ice storage system integrated with a packaged air

conditioning (DX) unit. For an ice storage system, integrated with a packaged air conditioning unit, charging and discharging involve circulating a heat transfer fluid between ice storage system's refrigeration cycle equipment and its storage section. Main components of an ice storage system integrated with DX unit are a compressor, a condenser, an evaporator and an ice storage tank. The mathematical description of the ice storage model, "Packaged Thermal Storage Cooling Coil" in EnergyPlus, is described in [37]. Each of the three floors has a separate ice storage system sized according to their cooling needs. Available performance data from EnergyPlus is used for modeling ice storage units in this study.

Modes of operation: The developed ice storage model in EnergyPlus operates in six different modes of operations, including the off mode, the cooling-only mode (air cooled at the evaporator like a conventional cooling system), the cool-and-charge mode (cooling of air at the evaporator and storage tank simultaneously), the discharge-only mode (coil cools process air by discharging the storage tank), the cool-and-discharge mode (both cooling and discharging of storage tank) and the charge-only mode (charging of storage tank).

Ice storage size: The ice storage system should be sized to meet the total integrated and peak hourly load [23]. An undersized system will not be able to recover when the load exceeds its capacity and an oversized system diminishes its benefits being unnecessarily expensive and inefficient. For sizing ice storage systems, hourly cooling load for the 24-hour design day is required along with the shape of the load profile. An operating strategy, which defines the logic that dictates when each operating mode is to be energized and what control strategy should be implemented in each mode is required to achieve the design intent. Ice storage systems for each floor are sized according to ASHRAE 0.4\% (actual outdoor hourly temperatures being greater than the design temperatures 35 hours of all annual hours) design day conditions (Note: ASHRAE = American Society of Heating, Refrigerating, and Air-Conditioning Engineers). It is advisable to use conservative selection of design temperatures to recover if design loads are exceeded [51]. An ice storage system sized for full storage can operate under different operating strategies including partial mode of operation as full storage determines the maximum storage size required to completely eliminate DX unit operation. The storage capacities for bottom, middle and top floors ice storage system used in this study are 6.02GJ, 6.84GJ and 6.81GJ, respectively.

\section{The proposed model}

Typically a DR event on a weekday can be at any time between $1 \mathrm{pm}$ to $7 \mathrm{pm}$ during a hot summer day [52, 53]. The study has been performed for a summer season when the cooling load is high during afternoon hours. The DR event selected for this analysis is between $2 \mathrm{pm}$ to $5 \mathrm{pm}$. An integrated control strategy is developed for DR, PV and ice storage systems. Based on the demand reduction signal from the utility, viable options among PV, ice storage and DR or their combination can be used to reduce peak load. In this study, the simulation is performed at 1 minute intervals. 
The proposed integrated model works as follows, PV output is firstly utilized to meet the building peak demand as it contributes towards usage of low-carbon energy. PV output is available all day but is dependent upon weather conditions. After exhausting PV output, the ice storage option is considered as it does not impact occupant thermal comfort. This is then followed by the DR option by controlling lights, cooling set points and plug loads in each zone while maintaining thermal and visual comfort at recommended standard levels. These three technologies along with their various combinations should help reduce peak load.

Figure 2 shows the proposed model and is explained as below:

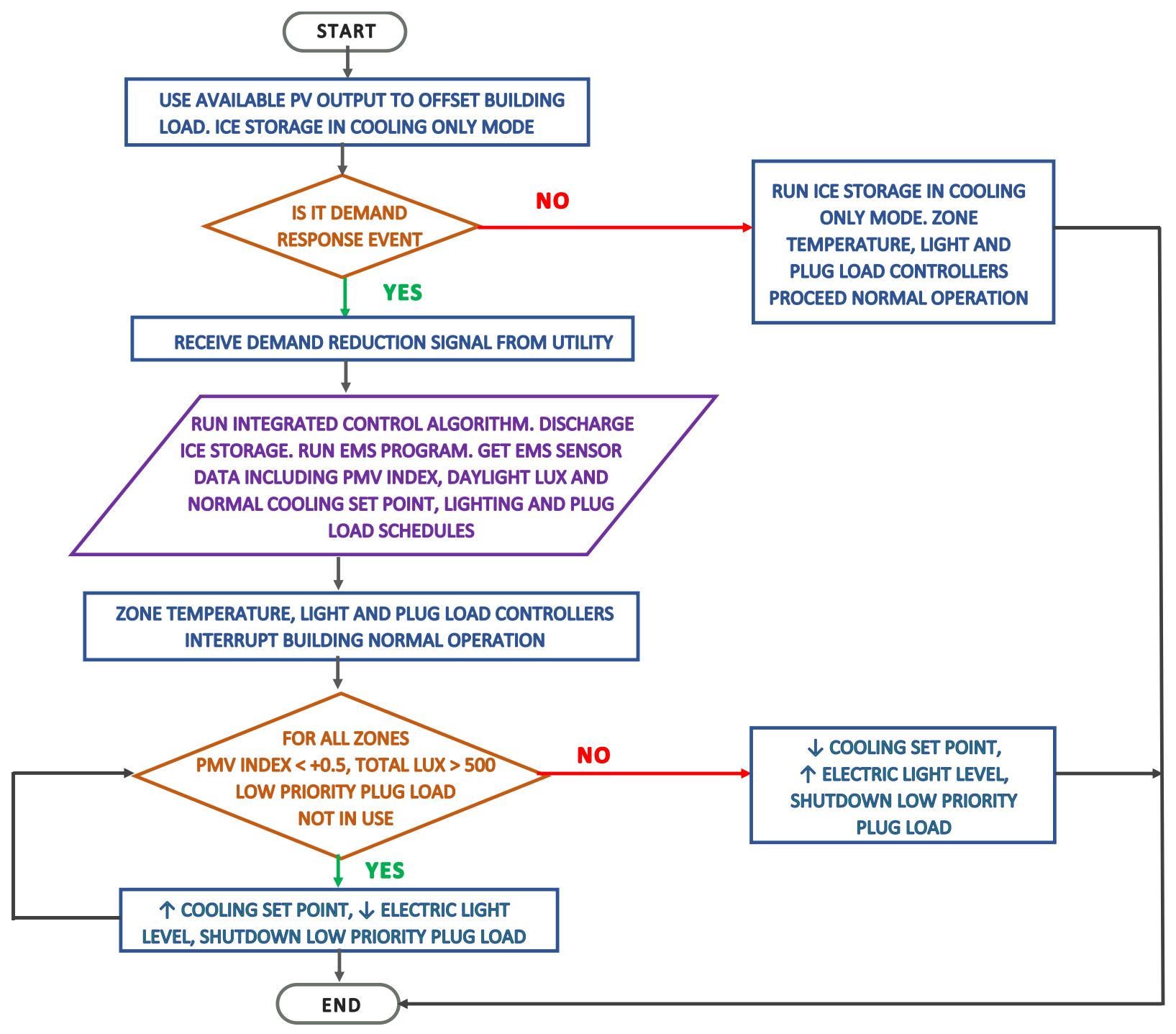

Fig.2 Proposed integrated control model for building end-use loads, PV and ice storage

\subsection{PV operating strategy}

Different PV operating schemes are available in EnergyPlus, which make the PV runs at requested power levels, including baseload, demand limit, track electrical, track schedule, track meter, follow thermal and follow thermal limit electrical [37]. The baseload scheme is used for the grid tied PV system installed on the rooftop of the simulated medium-sized office building. 
Under this scheme, the PV remains in operation even if the generated power exceeds building electrical demand. The surplus

power is fed back to the grid. PV output is the first to be used to offset building loads as it produces low carbon energy. Additional building electricity demand not met by PV is purchased from the utility.

\subsection{Ice storage operating strategy}

Next ice storage operation is considered, which reduces building cooling demand and modulates chiller operation to dampen the variability of PV output. Two types of ice storage control strategies are investigated in this study: full ice storage and partial ice storage. Their operating strategies as developed in the EnergyPlus's Energy Management System (EMS) program are described below.

In a full ice storage system, DX unit operation is eliminated completely during a DR event and the building cooling load is met by storage discharge only, i.e., the ice storage system is in the discharge-only mode during the DR event. Before the start of the DR event, from 12 noon to 2pm, the ice storage unit operates in the cooling-only mode where the building cooling demand is met by DX cooling only, no storage discharge. During the DR event, $2 \mathrm{pm}$ to $5 \mathrm{pm}$, the system is in the discharge-only mode, i.e., cooling is provided by storage discharge only. If the ice tank is depleted before $5 \mathrm{pm}$ and cooling load remains, the system switches to DX cooling. After the end of the DR event, the system again switches to the cooling-only mode until 8pm. From 8pm to 12 noon, the system is in the cool-and-charge mode, where the building is cooled with DX along with charging of the ice tank. While operating in the cool-and-charge mode if the tank charges up to $99 \%$ before 12 noon, the system switches to the coolingonly mode.

In a partial ice storage system, the DX unit along with storage discharge meets the building's cooling load. Before the start of the DR event, from 12 noon to 2pm, the ice storage unit operates in the cooling-only mode. During the DR event, $2 \mathrm{pm}$ to $5 \mathrm{pm}$, the system is in the cool-and-discharge mode where cooling is provided by the DX unit and storage discharge. If the ice tank is depleted before 5pm and cooling load remains, the system switches to DX cooling. After the end of the DR event, the system again switches to the cooling-only mode until $8 \mathrm{pm}$. From $8 \mathrm{pm}$ to 12 noon, the system is in the cool-and-charge mode. While operating in the cool-and-charge mode the tank is allowed to charge up to 55\% to avoid excessive energy consumption to charge a large storage. If the tank is charged up to $55 \%$ before 12 noon, the system switches to the cooling-only mode.

\subsection{End-use loads control (DR)}

A DR algorithm is designed in EMS to control HVAC, lighting and plug loads. The end-use load control response is in minutes. Occupant thermal comfort is measured by using the thermal comfort index, Predicted Mean Vote (PMV) [9]. Comfortable range for PMV is between -0.5 and +0.5 [54]. Occupant visual comfort is measured by illuminance, index for assessing the quantity of light [55]. Light levels for office space are maintained at 500 lux as recommended by ASHRAE and Illuminating Engineering Society of North America (IES) standard for office buildings [56, 57]. EMS sensors retrieve 
operating cooling set point, light and plug load schedules, illuminance levels and PMV index and provide them as input to the EMS program. EMS actuators based on the control decision actuate temperature, light and plug load controllers to override building operation.

HVAC control: During a DR event, each zone's cooling set points are altered from their normal operating set points of $24^{\circ} \mathrm{C}$, described in Section 2.1, as long as the PMV index remains within comfortable range and maximum peak load savings can be obtained.

Light control: Perimeter zones have photosensors to communicate real time zone illumination levels to the EMS. When lighting set point is exceeded, the lights are dimmed until the lighting set point is met; when there is enough daylight to maintain illumination levels all electric lights can be shut down. During a DR event light control operates as follows for the core and perimeter zones:

a) For core zones, which do not receive daylight, electric light levels are reduced if the current electric illuminance level is greater than 500lux.

b) Perimeter electric lights are completely shut down if daylight illuminance exceeds 500lux.

c) In case daylight illuminance is less than 500lux, electric light levels in each perimeter zone remain low as long as the relevant zone's daylight and electric illuminance together produce 500 lux.

Plug load control: During a DR event low priority plug loads (including $50 \%$ miscellaneous appliances - like, cell phone or iPad chargers, table radio, adding machine, battery charger, portable stereo, portable CD player, stapler, corded phone, etc.), all portable fans and water coolers in each zone are shutdown to achieve peak load savings.

\subsection{Coordinated control of $P V, D R$ and ice storage}

Various combinations of PV, DR and storage are simulated to determine the building's peak load reduction and energy savings potentials. Different scenarios are simulated by replacing the simulated building's conventional DX unit with the modeled ice storage system and activating various EMS actuators as explained in Table 2. When the load control actuator status is set to "ON", this implies that the light, temperature and plug load control is activated. It is deactivated when the load control actuator status is set to "Null". The ice storage actuator can be set to either "Cooling only", which implies that ice storage represents a conventional DX unit, or "Discharge", which implies that ice storage is operated in discharge mode (either full or partial control strategy). For PV control actuator status, " 1 ” implies that PV output is available, and " 0 " implies that PV output is disabled. For example, to demonstrate a DR event simulation, load control actuators status is set to "ON"; ice storage actuator is set to "Cooling only"; and the PV control actuator status is set to " 1 ".

Table.2 PV, DR and ice storage potential of the simulated building

\begin{tabular}{l|l} 
Scenarios & EMS actuator status \\
\hline
\end{tabular}




\begin{tabular}{|l|c|c|c|}
\hline & $\begin{array}{c}\text { Load control actuator } \\
\text { status }\end{array}$ & $\begin{array}{c}\text { Ice storage mode of } \\
\text { operation }\end{array}$ & $\begin{array}{c}\text { PV control actuator } \\
\text { status }\end{array}$ \\
\hline DR & ON & Cooling only & 0 \\
\hline Ice storage & Null & Discharge & 0 \\
\hline PV & Null & Cooling only & 1 \\
\hline PV and DR & ON & Cooling only & 1 \\
\hline PV and ice storage & Null & Discharge & 1 \\
\hline DR and ice storage & ON & Discharge & 0 \\
\hline PV, DR and ice storage & ON & Discharge & 1 \\
\hline
\end{tabular}

Simulation results obtained by these different scenarios are compared with the building demand when being cooled with the conventional DX unit, as discussed in the subsequent section.

\section{Simulation Results and Discussions}

\subsection{Building end-use loads profile}

Figure 3 shows the power consumption of major end-use loads in the simulated medium-sized office building with a conventional DX unit and the outdoor air temperature profile for a typical summer day used in this study. From 12 noon to about $6 \mathrm{pm}$ outside air temperatures are higher than $30^{\circ} \mathrm{C}$. This increase in outside dry bulb temperature increases building cooling load in the afternoon. The power consumption profile follows occupancy data along with HVAC and lighting load usage depicted in Section 2.1. There is a power surge at 6am as the HVAC system starts to operate and there is an immediate cooling demand as the cooling set points of all zones are reduced from $26.7^{\circ} \mathrm{C}$ to $24^{\circ} \mathrm{C}$. Building and HVAC peak loads of $223.40 \mathrm{~kW}$ and $107.34 \mathrm{~kW}$, respectively occur at 4:10pm.

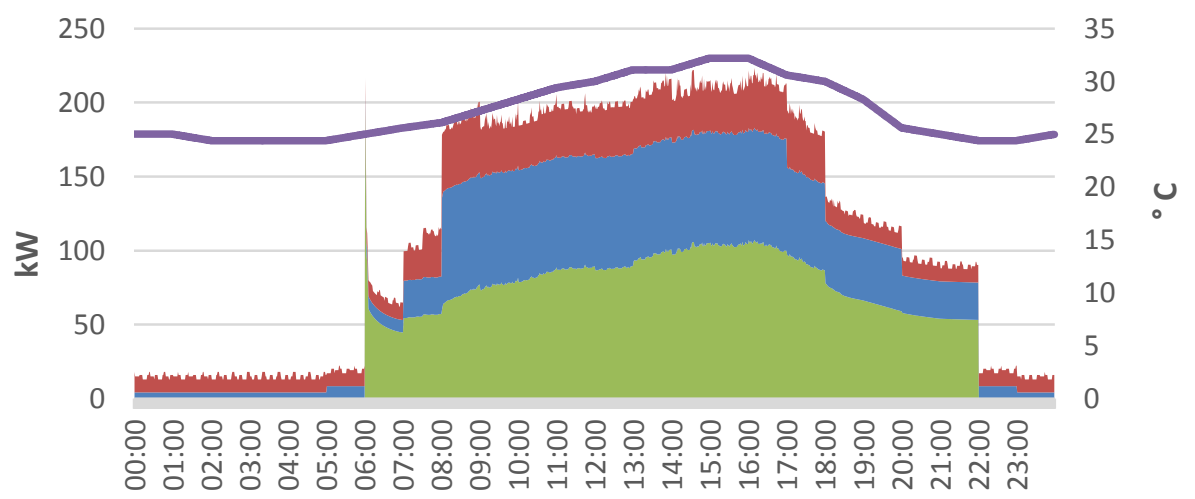

Time of Day

HVAC power consumption $\quad$ Lights power consumption
Plug loads power consumption $\quad$ Outdoor dry bulb temperature

Fig. 3 Power consumption of major end-use loads for the simulated medium-sized office building for the simulation day

\subsection{PV system potential}

Figure 4 shows the power output for PV sized to cover $65 \%$ of the building roof area in response to the sky clearness factor, 
greater than 6. The sky clearness factor for the simulated day is at its maximum, about 3.2, at 11:30am. It is at this time that the PV generates maximum output, about $82 \mathrm{~kW}$, which does not coincide with the building peak demand. During late afternoon hours building demand is higher but PV output gets lower. After 11:30am PV output starts to decrease but from around 2pm to 2:30pm starts to increase again, going up to $56.41 \mathrm{~kW}$ as the sky clearness factor increases to 2 . For the simulated day the building's total electricity consumption is $2786 \mathrm{kWh}$ and $\mathrm{PV}$ production is $550 \mathrm{kWh}$.

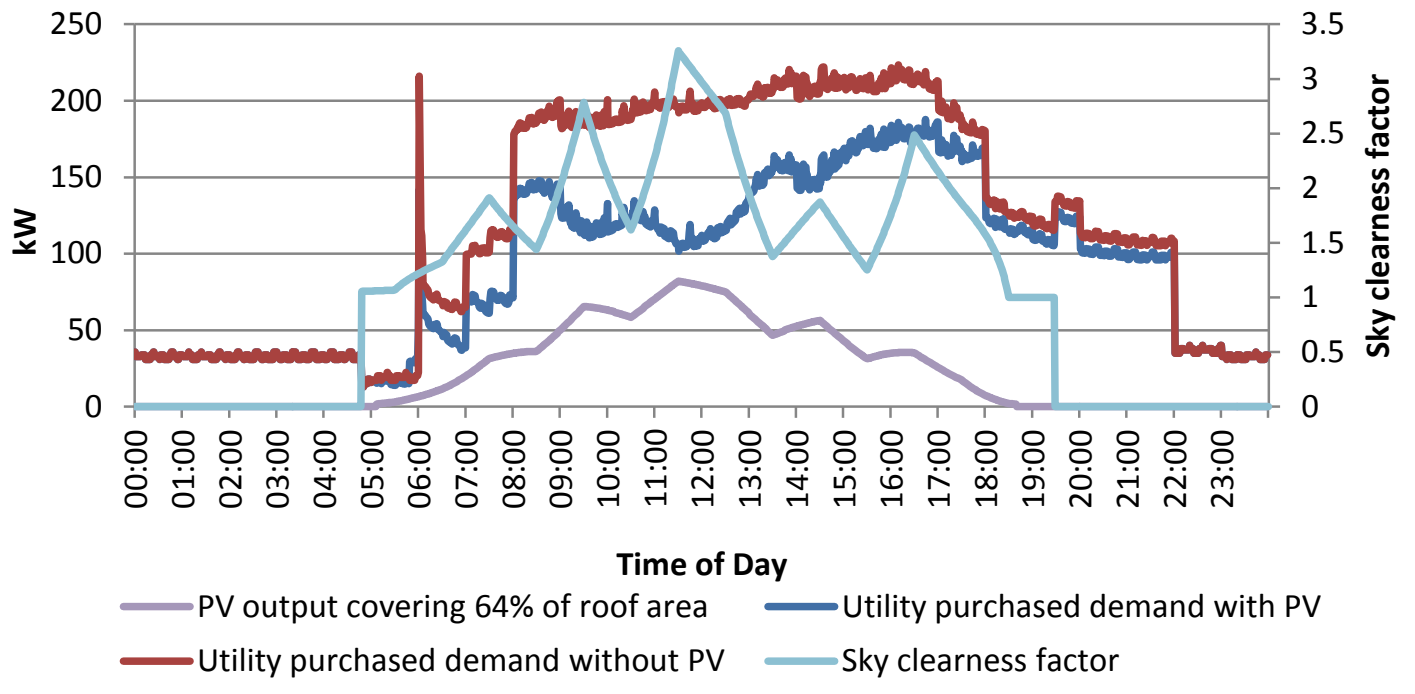

Fig. 4 Power generated by PV and purchased from utility for the simulated building for the simulation day

The PV unit - covering $65 \%$ of building roof area - produces $35.52 \mathrm{~kW}$ at $4: 10 \mathrm{pm}$, reducing utility purchased peak demand from $223.40 \mathrm{~kW}$ to $185.91 \mathrm{~kW}$, a decrease of $17 \%$.

\subsection{Ice storage system potential}

Two control strategies of an ice storage system during a DR event are investigated including full storage and partial storage. Figures 5 and 6 show the building and HVAC power consumption profiles with full and partial ice storage systems, respectively. There is a power surge at $6 \mathrm{am}$ as cooling set points of all zones reduce to $24^{\circ} \mathrm{C}$. As shown in Figure 6, the full ice storage system almost completely eliminates DX unit operation during a DR event by discharging storage, whereas the partial ice storage partially reduces DX unit operation during a DR event. At the end of a DR event there is an increase in power consumption as the ice storage switches to the cooling-only mode and compressors operates at full load to provide DX cooling. 


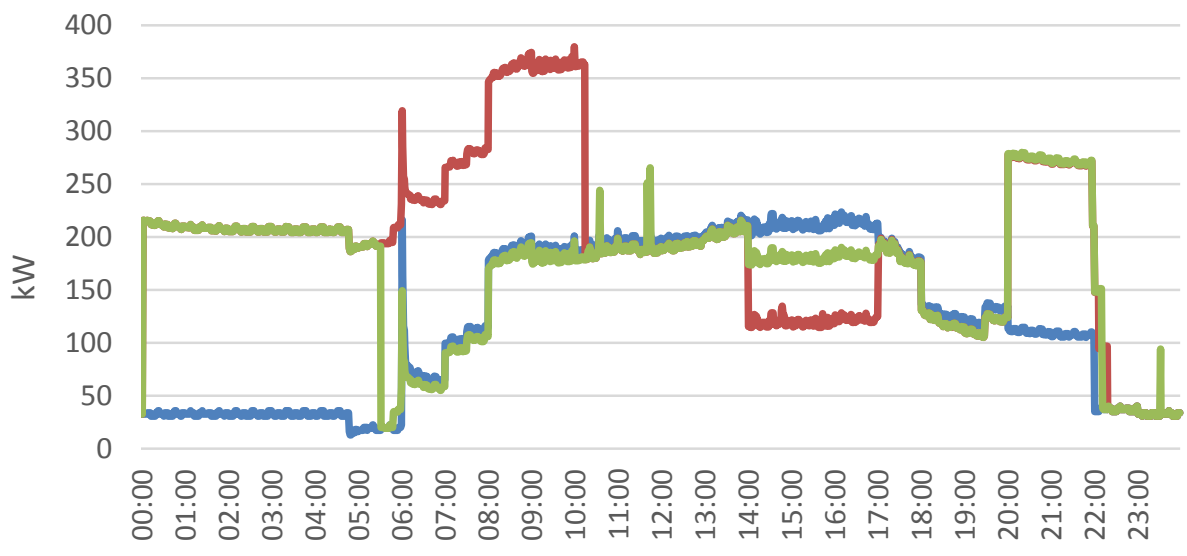

Time of Day

Conventional DX unit $\quad$ Full ice storage $\quad$ Partial ice storage

Fig.5 Simulated building power consumption profiles with and without ice storage for the simulation day

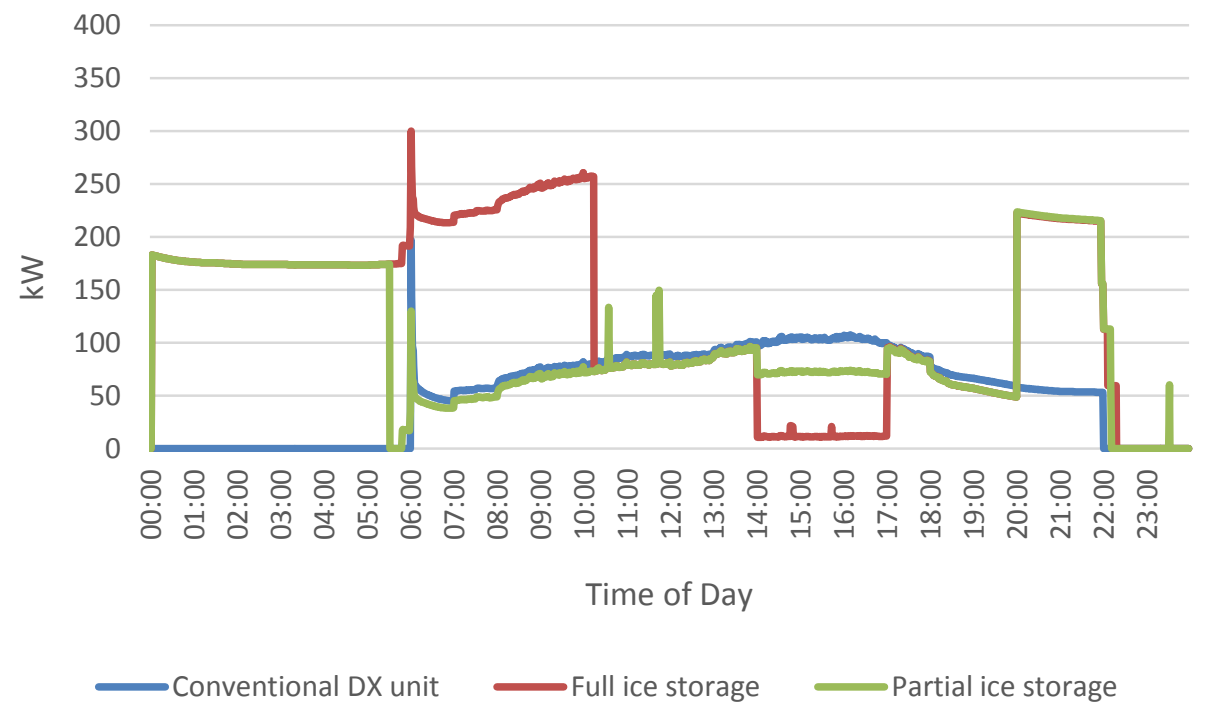

Fig.6 Simulated building's HVAC power consumption profiles with and without ice storage for the simulation day

Table 3 shows the peak load savings during a DR event for the two ice storage systems. The full ice storage unit reduces the building peak load at $4: 10 \mathrm{pm}$ by $42.54 \%$ whereas the partial storage unit reduces it by $14.85 \%$. Both systems however increase the buildings' overall energy consumption for the simulation day as ice is charged during unoccupied periods at lower temperatures hence the Coefficient of Performance (COP) reduces [25].

Table.3 Peak load savings and energy consumption with full and partial ice storage

\begin{tabular}{|c|c|c|c|c|}
\hline & \multicolumn{2}{|c|}{ Peak load at 4:10pm $(\mathrm{kW})$} & \multicolumn{2}{c|}{$\begin{array}{c}\text { Energy consumption for the simulation day } \\
\text { (GJ) }\end{array}$} \\
\hline & Building & HVAC & Building & HVAC \\
\hline $\begin{array}{c}\text { without ice storage } \\
\text { conventional DX unit) }\end{array}$ & 223.40 & 107.34 & 10.42 & 4.52 \\
\hline with full ice storage & 128.37 & 12.31 & 16.88 & 10.98 \\
\hline with partial ice storage & 190.22 & 74.15 & 14.52 & 8.63 \\
\hline
\end{tabular}


4.4. End-use loads control (DR) potential

Based on a demand reduction signal from a utility, end-use load control can be prioritized by zone based on their peak load reduction opportunity and impact on occupant comfort. For example, cooling set points for the bottom floor and core zones on all floors, which are cooler due to less solar heat gain than other floors, can be raised to meet the peak load reduction requirement. Similarly, on an extreme sunny day, based on a demand reduction signal, only lights in perimeter zones can be controlled to meet peak load savings. In this paper, all zones lights, cooling set points and plug loads are controlled to achieve maximum savings possible while maintaining occupant comfort needs. Figures 7 and 8 show building and HVAC power consumption profiles with EMS for the simulated building, respectively.

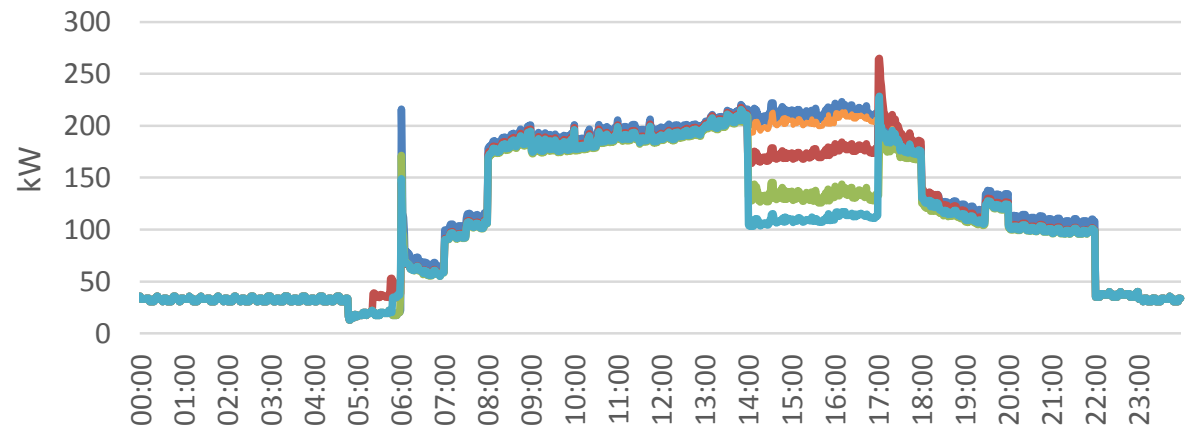

Time of Day
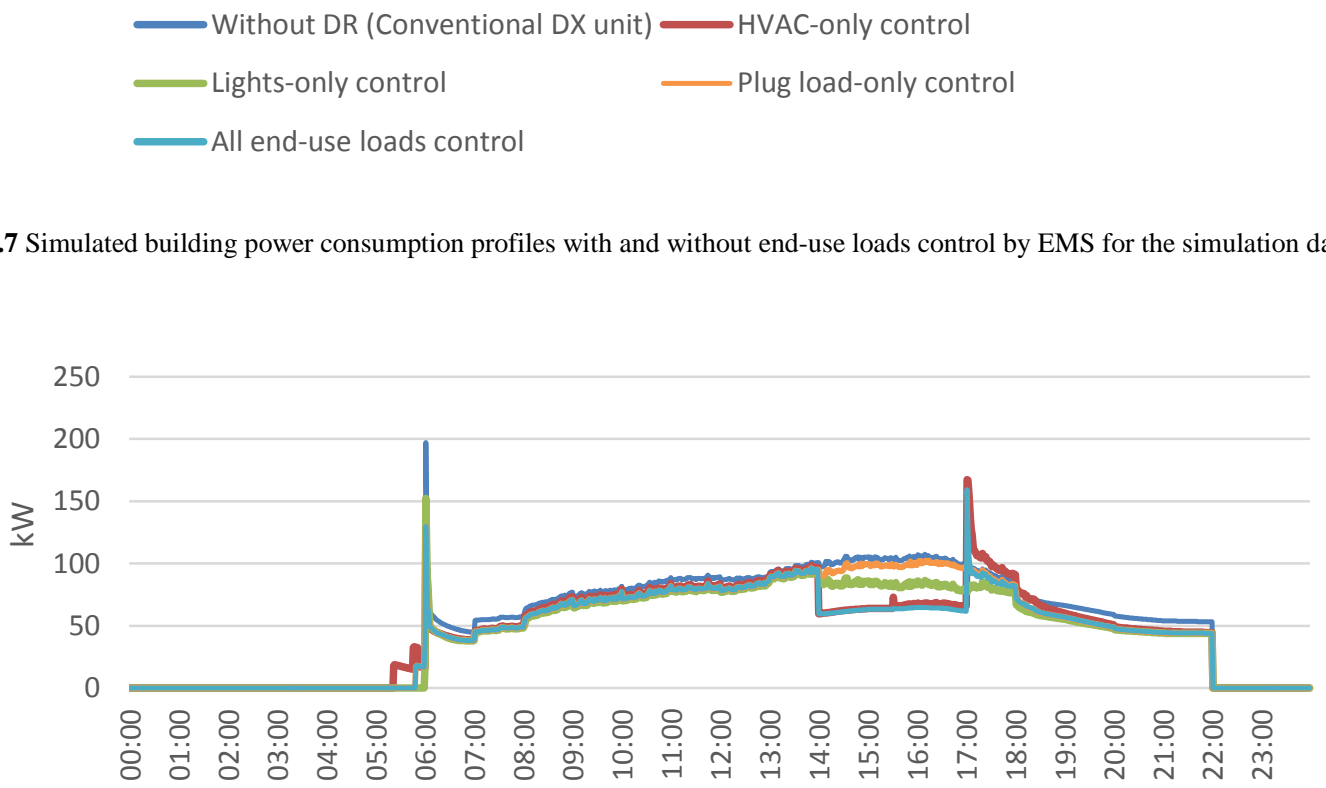

Time of Day

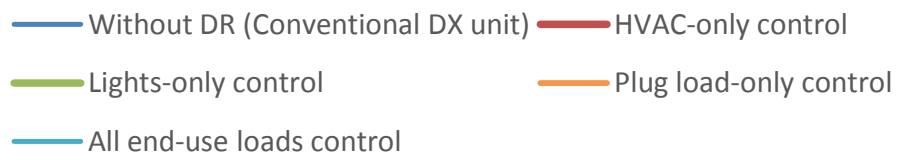


Fig.8 Simulated building's HVAC power consumption profiles with and without end-use loads control by EMS for the simulation day

The proposed DR approach reduces the building peak load at $4: 10 \mathrm{pm}$ from $223.40 \mathrm{~kW}$ to $116.41 \mathrm{~kW}$, representing a $48 \%$ decrease. The HVAC peak load at 4:10pm is reduced from $107.34 \mathrm{~kW}$ to $64.66 \mathrm{~kW}$, representing a $39.76 \%$ decrease. From Figure 9 it is observed that the HVAC load has a spike when the DR event ends at 5pm, which causes the HVAC load to increase from $61.65 \mathrm{~kW}$ to $159.17 \mathrm{~kW}$, representing an increase of $158 \%$. This demand rebound is due to the simultaneous HVAC operation after a DR event has ended, and can be reduced by slowly bringing back all zones' temperature set points to their nominal values or extending the DR duration to later hours, e.g. $7 \mathrm{pm}$ instead of 5pm. Extending a DR event duration will allow the previously deferred loads to be partially operated after working hours (e.g., between $5 \mathrm{pm}$ and $7 \mathrm{pm}$ ), when building occupancy has reduced and outside temperatures already get lowered [9]. As a result, less load compensation will be needed after a DR event ends at $7 \mathrm{pm}$.

Table 4 summarizes the peak load and energy savings with end-use loads control during the DR event. It can be observed that light control achieves maximum peak load and energy savings followed by cooling set point control. In particular, about $35.59 \%$ of the building peak load can be reduced with lights-only control; about $17.54 \%$ of the building load can be reduced with HVAConly control; and about $4.99 \%$ of the building peak load can be reduced with plug load-only control. Controlling all end-use loads results in an overall $48 \%$ peak load reduction in the building. This also results in the decrease of the overall building energy consumption by $13.82 \%$ for the simulation day.

It is also interesting to see that dimming lights and shutting down selected plug loads reduce HVAC power consumption due to the decrease in cooling loads. Specifically, lights-only control contributes to about $19.46 \%$ reduction in HVAC peak load; and plug load-only control contributes to about $5.08 \%$ reduction in HVAC peak load.

Table.4 Peak load and energy savings for simulated building with and without end-use loads control by EMS for the simulation day

\begin{tabular}{|c|c|c|c|c|c|c|c|c|}
\hline & \multicolumn{4}{|c|}{ Peak load at 4:10pm (kW) } & \multicolumn{4}{|c|}{ Energy consumption for the simulation day (GJ) } \\
\hline & Building & HVAC & Lights & Plug loads & Building & HVAC & Lights & $\begin{array}{l}\text { Plug } \\
\text { loads }\end{array}$ \\
\hline $\begin{array}{c}\text { Without DR } \\
\text { (Conventional DX unit) }\end{array}$ & 223.40 & 107.34 & 75.73 & 40.33 & 10.42 & 4.52 & 3.42 & 1.88 \\
\hline HVAC-only control & 184.21 & 68.15 & 75.73 & 40.33 & 9.83 & 3.93 & 3.42 & 1.88 \\
\hline Lights-only control & 143.89 & 86.45 & 17.11 & 40.33 & 9.13 & 3.87 & 2.79 & 1.88 \\
\hline Plug load-only control & 212.26 & 101.89 & 75.73 & 34.64 & 9.99 & 4.12 & 3.42 & 1.85 \\
\hline
\end{tabular}

\section{5. $P V$, ice storage and DR potential}

Coordinated control of DR strategy, PV and ice storage systems is implemented in the simulated medium-sized office building and presented in this Section. Figures 9 and 11 show the building and HVAC power consumption profiles by implementing various combinations of DR, PV and full ice storage systems, respectively. Figures 12 and 13 show the building and HVAC power consumption profiles by implementing various combinations of DR, PV and partial ice storage systems, respectively. 
In all scenarios, at the end of the DR event, at 5pm, the system is immediately brought back to its normal operation, i.e.,

cooling set points are reduced to $24^{\circ} \mathrm{C}$ and in case of ice storage operation, the cooling system switches to DX cooling only. In case of full storage, the compressor has to start up to provide DX cooling by cycling the refrigerant to cool the building air. In case of partial storage, the compressor is already operating during the DR event and partly meets the cooling load along with storage discharge. At the end of the DR event, the DX unit alone has to meet the cooling load. It is interesting to note that for the full storage, DR and PV combination (Case 5a), from 2pm to around 2:40pm building power consumption is zero and there is some surplus PV generation available shown in Figure 10. Surplus power reaches a maximum of 6kW at around 2:30pm and decreases afterwards. This is due to the decrease in building load as a result of the operation of DR and ice storage, as well as due to the increase in PV generation during this time as seen in Figure 4 going up to $56.41 \mathrm{~kW}$ and then decreasing again. The building acts as an energy generating unit or a positive energy building. From figure 12, DR and PV combination (Case 2) and DR, PV and partial ice storage combination (Case 5b) produce almost similar load shapes during DR event. This can be explained as follows, for Case 5b, the DX unit is operating along with partial storage discharge to meet the cooling load which has been reduced by employing DR strategy. Due to the reduced cooling load impact of partial storage is not significant. It is also observed from Figures 9, 11 to13 - that for Case 4a and 4b - more ice is discharged during the DR event than other cases which have DR strategy deployed, reducing the building cooling load, as a result the ice tank is charged for a longer time duration, until around $10 \mathrm{pm}$, to get completely charged up.
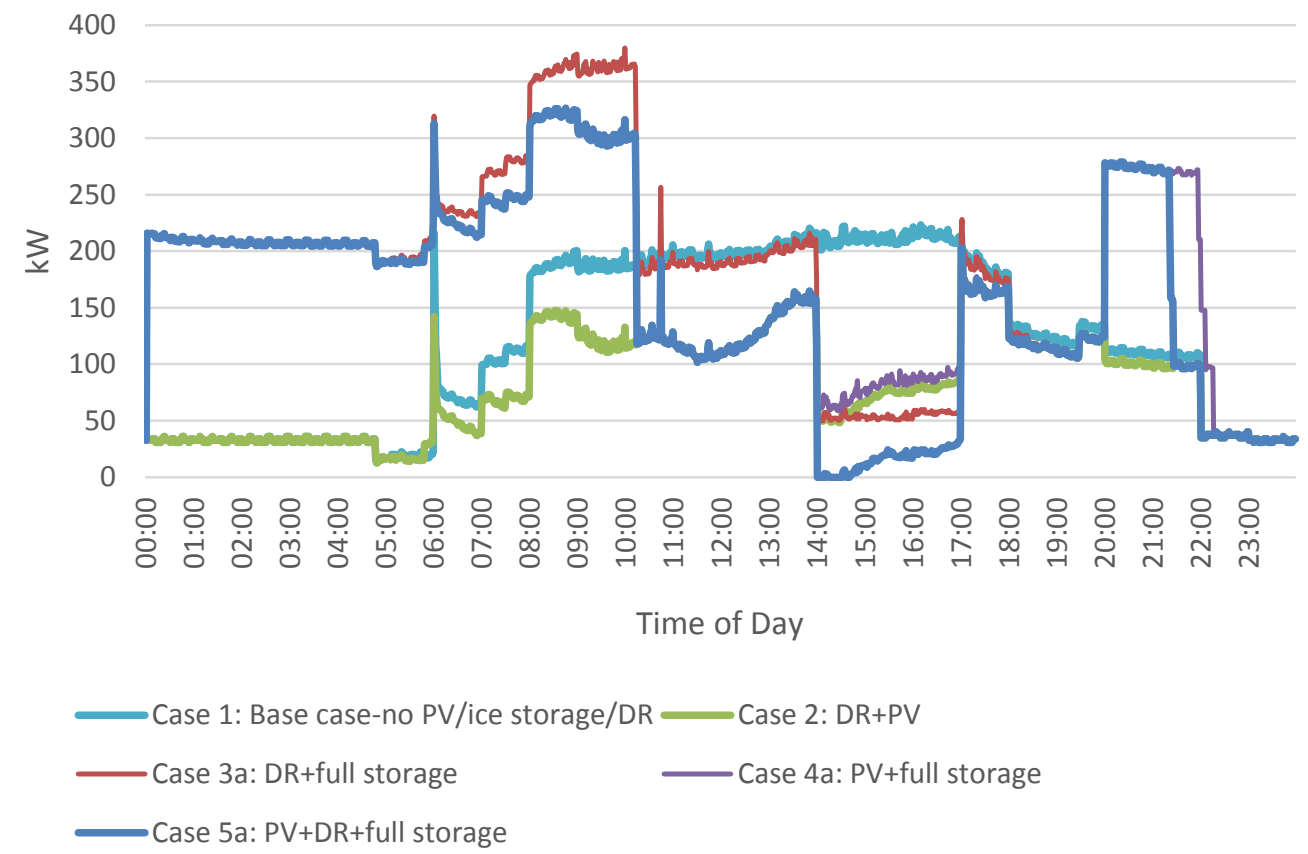


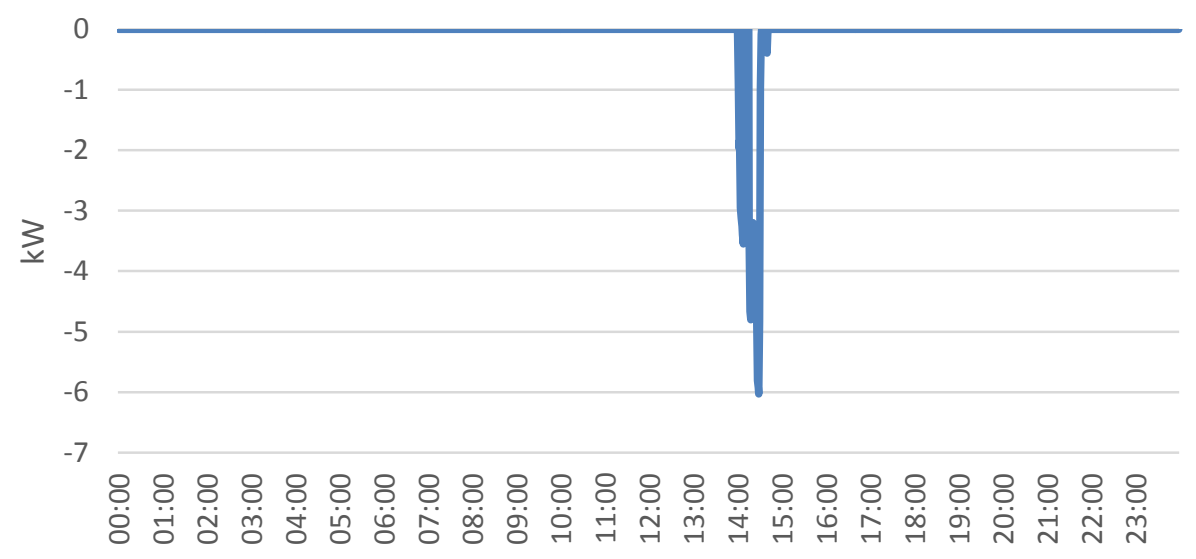

Time of day

1

Fig. 10 Simulated building surplus PV power generation for Case 5a for the simulation day

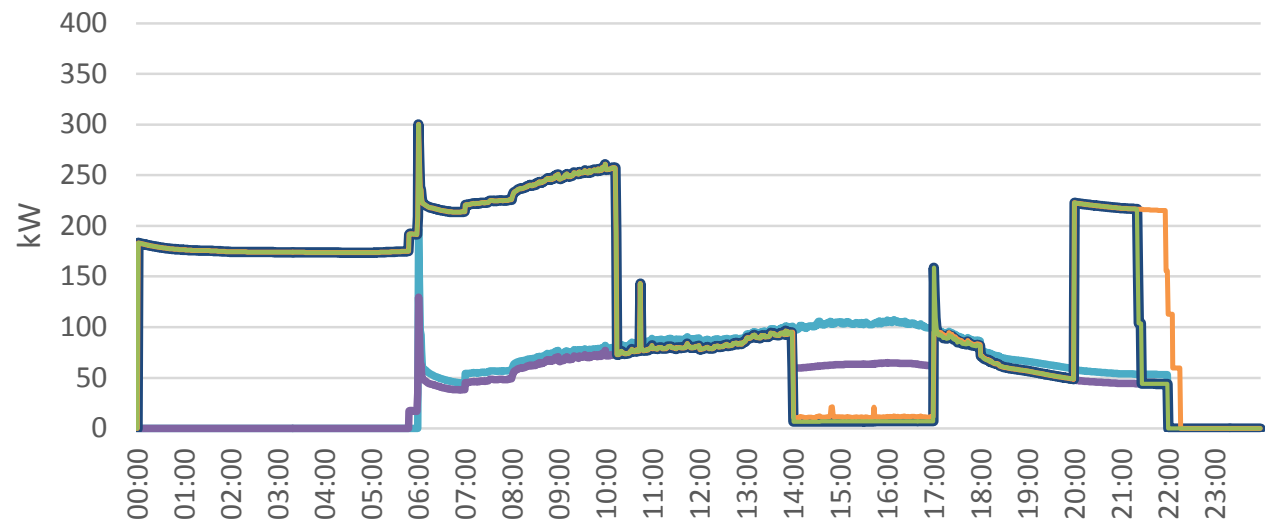

Time of Day

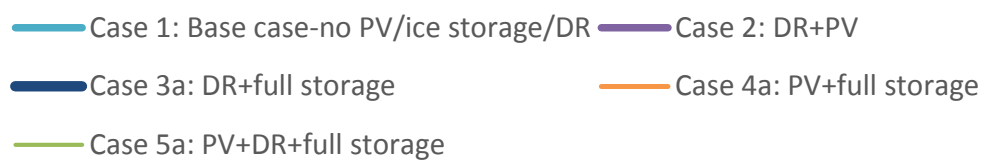

Fig. 11 Simulated building's HVAC power consumption profiles with combinations of PV, full ice storage and DR for the simulation day 


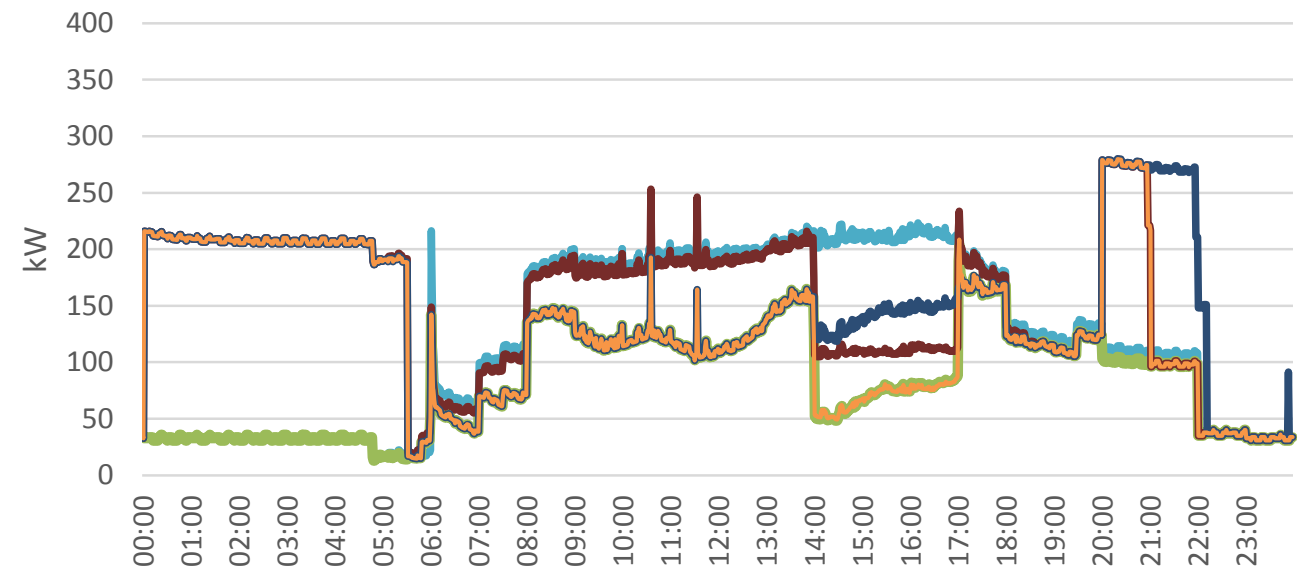

Time of Day

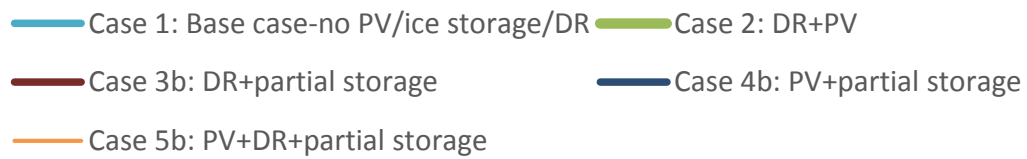

Fig. 12 Simulated building power consumption profiles with combinations of PV, partial ice storage and DR for the simulation day

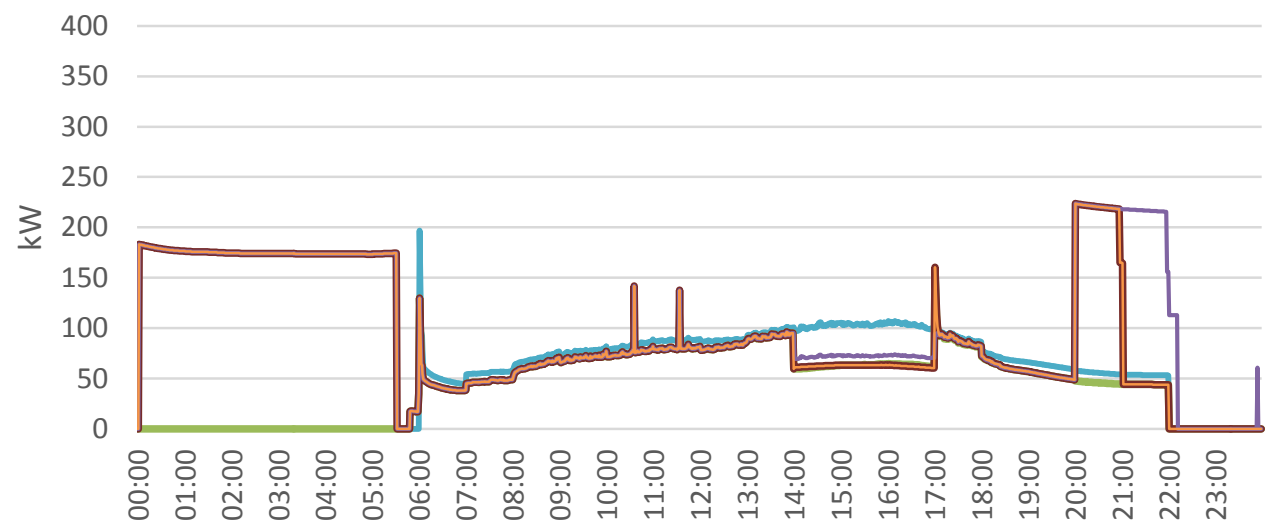

Time of Day

3

Case 2: DR+PV

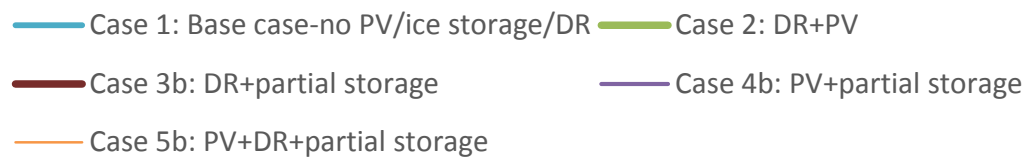

Fig. 13 Simulated building's HVAC power consumption profiles with and without PV, partial ice storage and DR for the simulation day

Table 5 summarizes the peak load and energy consumption of the simulated building when various combinations of DR, PV and ice storage are deployed.

Notice that while the building peak demand can be drastically decreased in all scenarios with ice storage, implementing ice storage (either full or partial) will result in an increase in overall building and HVAC energy consumption as there is a need to charge the storage at night. On the other hand, scenarios without ice storage in Case 2 (combination of PV and DR), Case 6 (PVonly) and Case 7 (DR-only) reduce not only the peak load but also the overall energy consumption of the building. 
Full ice storage together with DR and PV (Case 5a) achieves the highest peak load savings, i.e., about $89.51 \%$ reduction in the building peak load. Implementing full storage alone (Case 8a) results in a peak load saving of about $42.54 \%$ and the highest building energy consumption, an increase of about $62 \%$ from the base case with no PV, DR or ice storage, as there is no PV to provide excess generation or DR strategy to reduce end-use loads during the DR event. DR-only (Case 7) and DR and PV together (Case 2) achieve more building peak load savings than full storage alone (Case 8a) and at lower building energy consumption. DR-only is able to achieve more peak load savings than full storage alone as DR raises the cooling set points lowering HVAC consumption and also shuts down lights (which achieves maximum peak load savings) and plug loads which further reduce HVAC consumption.

Partial ice storage together with DR and PV (Case 5b) achieves higher building peak load savings than full ice storage with PV (Case 4a) but with lesser energy consumption. Partial storage alone (Case 8b) achieves the lowest building peak load savings of about $14.85 \%$ and the increase in building energy consumption is about $39.35 \%$. However, if partial storage is implemented with DR (Case 3b) building peak load reduces by $48.67 \%$ and the increase in building energy consumption is about $25.53 \%$. It is interesting to note that DR and PV combination (Case 2) produces peak load savings comparable to PV, DR and partial storage operating together (Case 5b) as the DX unit is operating along with storage discharge to meet the cooling load which has been reduced by DR.

Table.5 Peak load savings and energy consumption with various combinations of DR, PV and ice storage

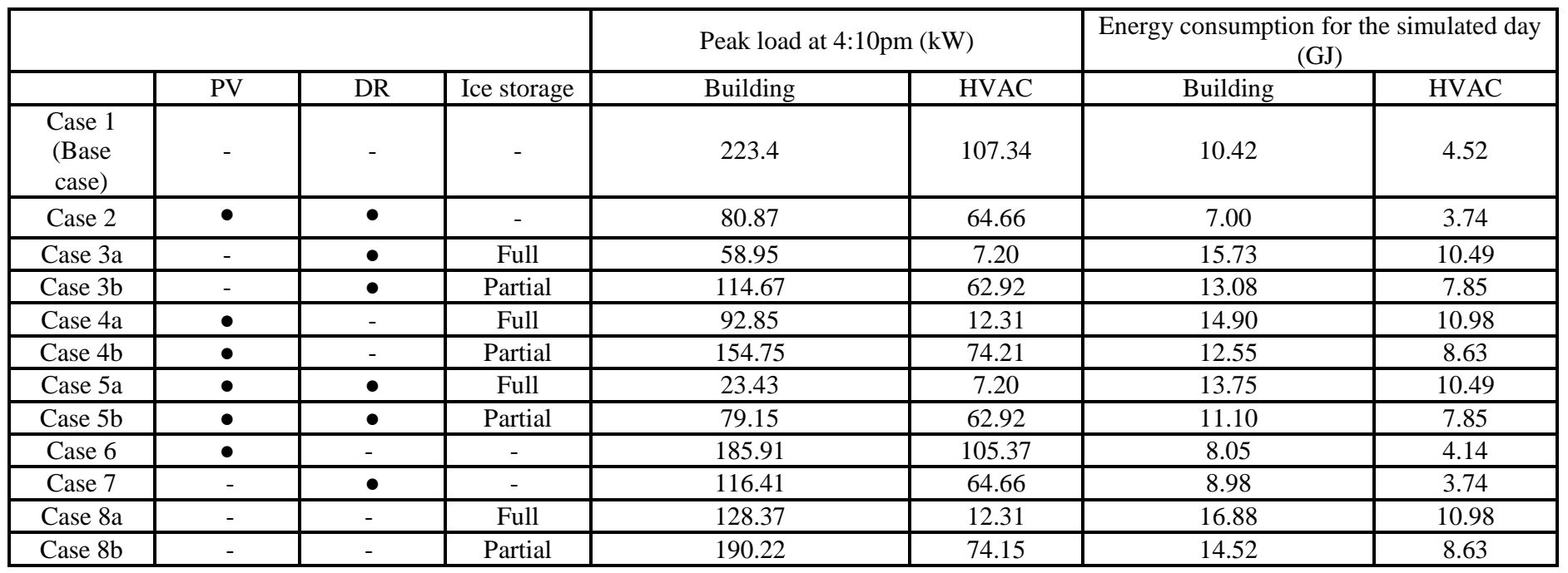

17

The above analysis provides building owners and electric utilities an insight into what load shapes and energy savings can be achieved by deploying various technologies. Results show that in addition to DR and ice storage, PV helps to further reduce the demand during high tariffs. Ice storage can shift the cooling demand to low night time tariffs. Reduced demand during high tariffs and spreading building demand over a day provide benefits to both building owners and utilities. Utilizing ice storage or DR with PV avoids the need of a very large on-site PV system as both ice storage and DR reduce building electric load. By 
operating PV with a full ice storage system and deploying DR, a commercial building can act as a generating unit with surplus PV energy that can be sent back to the grid. While the initial cost would be high due to the installation of PV and ice storage, the building's operational costs would be lower due to the use of DR, renewable energy and ice storage. This shows a stepping stone towards net-zero energy buildings.

\section{Conclusions}

Integration of renewable and storage at the utility side has usually been discussed in studies but not at the customer side with demand responsive buildings. This paper studies the integrated automation of DR, PV and ice storage, by means of dynamic simulations, that enables a building to meet the utility's demand reduction target through viable combinations of DR, PV and ice storage. Research findings indicate that PV-only, DR-only and their combination reduces both building peak load and energy consumption. Introducing ice storage increases overall building energy consumption but can provide significant peak load savings. Combining full storage together with DR and PV can achieve maximum peak load savings at the expense of increased energy consumption. However, DR and PV together can also achieve significant building peak load savings at reduced energy consumption. Operating partial storage with PV and DR achieves similar peak load savings as DR and PV operating together. generation. It should be noted that, a typical summer day has been analyzed in this paper to demonstrate the applicability of the proposed automation tool. Since there is always day-to-day variability in weather patterns, this will result in variation of peak reduction and energy savings potentials of a building throughout a year.

This research benefits building owners/operators by providing an improved understanding of building's load shapes as a result of performing DR, install PV and ice storage systems to maximize their building's economic benefits while being sensitive to occupant thermal and visual comfort. The knowledge gained through this research will help researchers develop new and improved controls for reducing building and distribution network's peak load.

\section{Acknowledgement}

This material is based upon work supported by U.S. National Science Foundation under Grant\# ECCS-1232076.

\section{References}

1. Motegi, N., et al., Introduction to Commercial Building Control Strategies and Techniques for Demand Response. May 2007, LBNL 59975.

2. Watson D., S. Kiliccote, N. Motegi, and M. Piette, Strategies for demand response in commercial buildings. Proceedings of the 2006 ACEEE Summer Study on Energy Efficiency in Buildings, August 2006.

3. Dubois, M.-C. and $\AA$. Blomsterberg, Energy saving potential and strategies for electric lighting in future North European, low energy office buildings: A literature review. Energy and Buildings, 2011. 43(10): p. 2572-2582.

4. Galasiu, A.D., et al., Impact of window blinds on daylight-linked dimming and automatic on/off lighting controls. Solar Energy, 2004. 76(5): p. 523-544.

5. Newsham, G.R., et al., Individual control of electric lighting in a daylit space. Lighting Research and Technology, 2008. 40(1): p. 25-41. 
6. Tzivanidis, C., K.A. Antonopoulos, and F. Gioti, Numerical simulation of cooling energy consumption in connection with thermostat operation mode and comfort requirements for the Athens buildings. Applied Energy, 2011. 88(8): p. 2871-2884.

7. Galasiu A.D., and J.A. Veitch, Occupant preferences and satisfaction with the luminous environment and control systems in daylight offices: a literature review. Energy and Buildings, 2007. 38(7): p. 728-742.

8. Shen E., Jia H., and Maulin P., Energy and visual comfort analysis of lighting and daylight control strategies. Building and Environment, 2014. 78: p. 155-170.

9. Sehar, F., M. Pipattanasomporn, and S. Rahman, A peak-load reduction computing tool sensitive to commercial building environmental preferences. Applied Energy, 2016. 161: p. 279-289.

10. Arnold, D., Sankar M., Auslander, D.M., , An architecture for enabling distributed plug load control for commercial building demand response. Innovative Smart Grid Technologies (ISGT), IEEE PES 2013: p. 1-6.

11. Weng, T., et al. Managing Plug-Loads for Demand Response within Buildings. in Proceedings of the ACM Workshop on Embedded Sensing Systems For Energy-Efficiency. October 2011. Seattle.

12. Location, location, location Domestic small-scale wind field trial report. 2009, Energy Saving Trust.

13. Gagliano, A., et al., Assessment of micro-wind turbines performance in the urban environments: an aided methodology through geographical information systems. International Journal of Energy and Environmental Engineering. 4(43).

14. Pandey, A.K., et al., Recent advances in solar photovoltaic systems for emerging trends and advanced applications. Renewable and Sustainable Energy Reviews, 2016. 53: p. 859-884.

15. Nolan, S. and M. O'Malley, Challenges and barriers to demand response deployment and evaluation. Applied Energy, 2015. 152: p. 1-10.

16. Wang, X., A. Palazoglu, and N.H. El-Farra, Operational optimization and demand response of hybrid renewable energy systems. Applied Energy, 2015. 143: p. 324-335.

17. Moura, P.S. and A.T. de Almeida, Multi-objective optimization of a mixed renewable system with demand-side management. Renewable and Sustainable Energy Reviews, 2010. 14(5): p. 1461-1468.

18. Puchegger, M., Electric load behavior and DSM potential of office buildings. Energy and Buildings, 2015. 100: p. 4349.

19. Wang, G., et al., Study on the promotion impact of demand response on distributed PV penetration by using noncooperative game theoretical analysis. Applied Energy.

20. Commercial Buildings Energy Consumption Survey Table E3A. Electricity Consumption (Btu) by End Use for All Buildings, 2003. $\quad$ Released: September, 2008; Available from: https://www.eia.gov/consumption/commercial/data/archive/cbecs/cbecs2003/detailed_tables_2003/2003set19/2003html /e03a.html.

21. Kintner-Meyer, MC., et al., The Role of Energy Storage in Commercial Building September 2010, Pacific Northwest National Laboratory (PNNL).

22. Dorgan, C.E. and J.S. Elleson, Design Guide for Cool Thermal Storage. 1993: ASHRAE.

23. ASHRAE, Thermal Storage, in ASHRAE Handbook - HVAC Systems and Equipment. 2012.

24.

25. Dincer, I. and M.A. Rosen, Thermal Energy Storage Systems and Applications. 2011, John Wiley \& Sons, Ltd

26. Arteconi, A., N.J. Hewitt, and F. Polonara, State of the art of thermal storage for demand-side management. Applied Energy, 2012. 93: p. 371-389.

27. Hasnain, S.M. and N.M. Alabbadi, Need for thermal-storage air-conditioning in Saudi Arabia. Applied Energy, 2000. 65(1-4): p. 153-164.

28. Limmeechokchai, B. and S. Chungpaibulpatana, Application of cool storage air-conditioning in the commercial sector: an integrated resource planning approach for power capacity expansion planning and emission reduction. Applied Energy, 2001. 68(3): p. 289-300.

29. Zhanbo, X., et al., Performance Analysis and Comparison on Energy Storage Devices for Smart Building Energy Management. Smart Grid, IEEE Transactions on, 2012. 3(4): p. 2136-2147.

30. Jubran, S., Modeling and Optimization of a Hybrid Solar PV-Powered Air Conditioning System with Ice Storage. 2011, Arizona State University.

31. Feitau K., M.Deru, and E. Bonnema, Evaluation Framework and Analyses for Thermal Energy Storage Integrated with Packaged Air Conditioning 2013, National Renewable Energy Laboratory (NREL).

32. U.S. Department of Energy, Commercial Reference Buildings. [cited 2015; Available from: http://energy.gov/eere/buildings/commercial-reference-buildings.

33. Commercial Buildings Energy Consumption Survey Data, Table B8. Year constructed, number of buildings, 2012. Released in March 2015 [cited 2016; Available from: http://www.eia.gov/consumption/commercial/data/2012/.

34. U.S. Department of Energy, EnergyPlus Weather Data. [cited 2015; Available from: http://apps1.eere.energy.gov/buildings/energyplus/weatherdata_about.cfm.

35. Thornton, B., et al., Technical Support Document: 50\% Energy Savings Design Technology Packages for Medium Office Buildings. 2009, Pacific Northwest National Laboratory (PNNL). 
36. Sehar, F., M. Pipattanasomporn, and S. Rahman, An approach for optimal demand management in commercial buildings considering occupant comfort. Energy, 2016.

37. EnergyPlus Web-Based Documentation. 2015 [cited 2015; Available from: http://bigladdersoftware.com/epx/docs/index.html.

38. Landau, C.R., Optimum Tilt of Solar Panels. 2014 [cited 2015 October]; Available from: http://www.solarpaneltilt.com/.

39. NREL. PVWatts Calculator. [cited 2015 October]; Available from: http://pvwatts.nrel.gov/pvwatts.php.

40. Denholm, P. and R. Margolis, Supply curves for rooftop solar PV-generated electricity for the United States. 2008, National renewable Energy Laboratory (NREL).

41. Paidipati, J., et al., Rooftop photovoltaics market penetration scenarios. 2008, National Renewable Energy Laboratory (NREL).

42. Melius, J., R. Margolis, and S. Ong, Estimating Rooftop Suitability for PV: A Review of Methods, Patents, and Validation Techniques. 2013, National Renewable Energy Laboratory (NREL).

43. Chaudhari, M., L. Frantzis, and T.E. Hoff, PV grid connected market potential under a cost breakthrough scenario. 2004, Navigant Consulting.

44. Olis, D. and G. Mosey, Integration of rooftop photovoltaic systems in St. Paul Ford site's redevelopment plans. 2015, National Renewable Energy Laboratory (NREL).

45. Solar Calculator. 2016; Available from: http://www.rbisolar.com/solar-calculator/.

46. A. Luque and S. Hegedus, Handbook of Photovoltaic Science and Engineering. (2nd edition) 2011, John Wiley \& Sons.

47. Camps, X., et al., Contribution to the PV-to-inverter sizing ratio determination using a custom flexible experimental setup. Applied Energy, 2015. 149: p. 35-45.

48. $\quad$ DC Loading of PV Powered Inverters. 2012, Advanced Energy Industries Inc.

49. Go Solar California. 2016 [cited 2016; Available from: http://www.gosolarcalifornia.org/equipment/.

50. PVI 60KW, PVI 77KW, PVI 90KW Installation and Operation Manual Commercial, Grid-Tied Photovoltaic Inverters. 2006, Solectria Renewables LLC.

51. Sehar, F., Impact of Ice Storage on Electrical Energy Consumption in Large and Medium-sized Office Buildings in Different Climate Zones in ECE. 2011, Virginia Tech.

52. PJM Demand Response. 2014 [cited 2014 November]; Available from: http://www.pjm.com/markets-andoperations/demand-response/dr-reference-materials.aspx.

53. CPS Energy: Demand Response. 2011 [cited 2014 November]; Available from: http://www.cpsenergysavers.com/commercial/start-saving/demand-response.

54. J. Toftum, R.V. Anderson, K.L. Jensen, Occupant performance and building energy consumption with different philosophies of determining acceptable thermal conditions. Building and Environment, 2009. 44(10): p. 2009-2016.

55. Carlucci, S., et al., A review of indices for assessing visual comfort with a view to their use in optimization processes to support building integrated design. Renewable and Sustainable Energy Reviews, 2015. 47: p. 1016-1033.

56. Illuminating Engineering Society of North America, IESNA Lighting Handbook. (9th edition) 2000, New York.

57. ASHRAE/IESNA Standard 90.1-1999. 